УДК 338.22

Д. ШІ. Мусостова

ФГБОУ ВО «Чеченский Государственный Университет», e-mail: goldzr@yandex.ru

\title{
T. В. Якубов
}

ФГБОУ ВО «Грозненский государственный нефтяной технический университет им. М.Д. Миллионщикова», Грозный

\section{МЕНЕДЖМЕНТ В ИННОВАЦИОННОМ ПРЕДПРИНИМАТЕЛЬСТВЕ}

Ключевые слова: менеджмент, инновации, инвесторы, венчурный фонд, развитие.

Все более широкую популярность набирает бизнес - литература, так или иначе связанная с менеджментом в предпринимательстве или искусством ведения бизнеса. Подобные труды широко известных авторов, незаметно, однако оказывают положительное влияние на мышление человека, который в течении длительного периода времени рассматривал предпринимателя как человека, который не смог реализоваться и реализовать свои идеи и способности, а во - вторых, как следствие первого, способствуют улучшению общей экономической ситуации в стране. В данной статье подробно описаны проблемы менеджмента в бизнесе, а также пути их решения с учетом государственной, частной и иной поддержки малого и среднего бизнеса, развивающегося в инновационном ключе на современном рынке. Роль и этапы венчурного финансирования малого предпринимательства. В статье представлен инновационный менеджмент в предпринимательстве и его отличие от традиционного способа управления. Бизнес сегодня значительно отличается от того, каким он был несколько десятилетий назад, что связано с трансформацией общества, его цифрового развития и, изменившиеся под весом данных факторов, предпринимательской культуры. Выстроить эффективный менеджмент сегодня и сложнее, и легче одновременно.

\section{Sh. Musostova}

Chechen State University, e-mail: goldzr@yandex.ru

\section{T. V. Yakubov}

Grozny State Oil Technical University named after M.D. Millionschikova, Grozny

\section{MANAGEMENT IN INNOVATIVE ENTREPRENEURSHIP}

Keywords: management, innovation, investors, venture capital fund, development.

Business literature is gaining more and more popularity, one way or another connected with management in entrepreneurship or the art of doing business. Such works by well-known authors, imperceptibly, however, have a positive effect on the thinking of a person who for a long period considered an entrepreneur as a person who could not be realized and realize his ideas and abilities, and secondly, because of the first, they help to improve the general economic situation in the country. This article is detailed problems of management in business are described in detail, as well as ways to solve them, taking into account state and other support for small and medium-sized businesses, developing in an innovative manner in the modern market. The role and stages of venture financing of small business. The article presents innovative management in entrepreneurship and its difference from the traditional way of management .Business today is significantly different from what it was a few decades ago, which is associated with the transformation of society, its digital development and, changed under the weight of these factors, entrepreneurial culture. Building effective management today is both more difficult and easier at the same time.

Большинство определений в литературных источниках ограничиваются следующим определением: предприниматель - это человек, занимающийся производством товаров или оказанием услуг, или хозяйственной деятельностью, на свой страх и риск и под свою ответственность. Современном мире, в настоящее время предпринимателя можно охарактеризовать более «красочно» и справедливо: человек, который работает над своими собственными способностями, идеями, верит в свои убеждения, учится, усердно работает, создает конкретно определенный продукт, что дает свободу делать то, о чем мечтал, сколько хочет и когда хочет. Естественно - это обеспечивает его гибкость в выборе рабочего времени, объёма работ и благосостояния и т.д., - это причины предприни- 
мательства, позволяющие в полной мере удовлетворить свои повседневные биосоциальные, то есть жизненные потребности. Распространенным заблуждением является и то, что только некоторые «особые» могут быть предпринимателями, поскольку человек должен родиться с необходимыми качествами. Это утверждение, однако, было опровергнуто, без сомнения. Предпринимателями становятся в силу внутренних или внешних обстоятельств, либо развитие общества, изменения конъектуры рынка, внутреннее побуждение, нереализованность т.д., но ими точно не рождаются. Все ведущие университеты и бизнес-школы мира, от Гарварда до Оксфорда, предлагают своим студентам курсы по ведению бизнеса и предпринимательству. Будущие лидеры бизнеса, тем не менее, считают, что традиционный способ обучение ведения бизнеса не актуален, как и сам менеджмент, что вскоре это уйдет в прошлое.

Современный рынок стимулируется инновациями, мобильностью и активностью. Появление Интернета и новых технологий изменило коммерческий ландшафт до неузнаваемости, для успешного ведения бизнеса в этих условиях требуется новый масштаб и способ мышления. Сегодня предприниматели должны осваивать новые технологические достижения и новые методы ведения бизнеса активнее, чем, когда - либо. Как бы странно это не звучало, все большее число компаний отказывается от традиционной иерархии управления и принимает единую структуру управления. Обычно стратегия управления бизнесом направлена на создание решений, которые могут помочь поднять организацию на более высокий уровень для улучшения и роста бизнес-процессов. Проще говоря, принятия решения по менеджменту бизнес-стратегии как правило, решает следующие четыре проблемы:

1. Исследование среды, в которой будет функционировать организация;

2. Позиционирование организации и своей роли в данной среде;

3. Постановка цели для удовлетворения потребностей организации с точки зрения долгосрочной, так и краткосрочной представления о том, что может предложить организация;
4. Установление цели организации по ведению бизнеса, заявленной как в финансовом, так и в стратегическом плане.

Развитие предпринимательства включает в себя реализацию различных факторов, функций и видов деятельности, связанных с ними. Предприниматель сталкивается с множеством проблем и возможностей при достижении своей цели. Прежде всего, человек, решивший заняться собственным делом, должен выбрать тип бизнеса. Предприниматель может заниматься индивидуальным предпринимательством (ИП) или являться учредителем акционерного общества. Тип организации определяет размер бизнеса. Так, предпочтение акционерному обществу следует отдавать в случае больших масштабов. Единоличное владение (ИП) считается более подходящим для малого и среднего бизнеса. Размер бизнеса зависит от нескольких факторов, таких как финансовый, технический и в зависимости от внимания рынка. Обычно предприниматель может начать свой бизнес в небольших масштабах и постепенно расширить его. Предприниматель начинает свой бизнес широко, когда чувствует, что может продвигать ожидаемые результаты и может привлечь достаточное количество средств.

После определения типа бизнеса, необходимо выбрать вид деятельности. Однако, у предпринимателя может быть готовой бизнес - проект, тогда, выбор типа бизнеса переходит на второе место. Предприниматель должен изучить рынок, чтобы узнать, может ли идея, продукт или услуга быть принята рынком или нет. Изучая рынок, предприниматель должен определить рыночный спрос на ожидаемые товары или услуги, приложить все усилия, чтобы выяснить ожидаемую стоимость товара или услуги. Таким образом, предприниматель должен знать, является ли бизнес прибыльным или нет. Это систематическое исследование рынка известно, как технико-экономическое обоснование. И только после тщательного изучения емкости рынка, принимается окончательное решение. Следующим этапом организации современного бизнеса и одновременно главной его проблемой является необхо- 
димость поиска финансовых ресурсов. Предприниматель нуждается в финансах для покупки основных средств, таких как земля и здания, машины и оборудование. Кроме того, финансы необходимы для выполнения требования бизнеса. Предпринимателю, возможно, придется организовать финансирование из различных ресурсов, чтобы накопить необходимый объем финансирования. На сегодняшний день существуют множество источников финансирования, которые могут заранее определять эффективность проекта или идеи. К ним можно отнести:

1. Государственное финансирование;

2. Кредиты банков;

3. Венчурное финансирование

4. Ангельское инвестирование.

В любом государстве одной из основных целей является обеспечение занятости и сокращения уровня безработицы в стране, следствием которого становится снижение социальной напряженности, экономический рост, пополнение бюджета за счет налогов на прибыль предприятий, подоходного налога и др. видов налогов. В условиях кризиса и безработицы государство начинает уделять большее внимание представителям малого и среднего бизнеса, поддерживая и стимулируя их различными инструментами, такими как, к примеру, безвозмездное финансирование бизнеса, налоговые льготы, каникулы и т.д. Государственное финансирование создания малого бизнеса производится через центры занятости населения. Признанный безработным гражданин может предоставить для рассмотрения специалистов собственный бизнес-план. В нем должна быть изложена суть планируемой деятельности, приведены сведения о необходимых материалах, оборудовании, технологиях, поставщиках, рабочей силе, месте размещения фирмы. [1]

Наиболее распространенными направлениями, по которым производится финансирование являются:

- Сельское хозяйство;

- Производство продукции;

- Инновационные бизнес - проекты.

Несомненным преимуществом государственной поддержки есть и остается безвозмездность финансирования. Но, стоит также отметить, что получить господдержку очень непросто. Для получения финансовых ресурсов предпринимателя придется немало приложить усилия и побегать по различным инстанциям для сбора всех необходимых документов. Возможно также взаимодействовать с другими начинающими предпринимателями, которые обеспечили требования к финансированию, чтобы получить представление о других потенциальных инвесторах. Некоторые неправительственные и полугосударственные организации могут также иметь возможность поддержки малого и среднего бизнеса, но где могут одновременно потребовать больше документации. Бюрократизм значительно усложняет задачу, однако, это не самое сложное. Как правило, для получения господдержки 50 \% финансовых ресурсов, необходимых для реализации проекта, должен внести сам владелец бизнеса. Некоторые правительственные учреждения, такие как министерство науки и технологий, сельского хозяйства, министерство охраны окружающей среды, как правило часто объявляет грантовый конкурс для молодых исследователей и предпринимателей, предлагающих инновационные идеи. Хотя их может быть недостаточно для создания предприятия, оно обеспечивает исходный капитал для покрытия начальных расходов. Чаще всего они могут не требовать погашения. Но выплаты могут быть тщательно отслежены на их целевое использование и в зависимости от эффективности развития нового предприятия, процесс финансирования будет осуществляться в рассрочку.

Кредитные учреждения выдают средства под проценты с приоритетом по следующим направлениям: сельское хозяйство, строительная отрасль, транспортные перевозки, производство продуктов питания, предоставлении услуг связи. Финансирование инновационного бизнеса в кредитных учреждениях не получило широкого распространения из-за высокой степени риска. Наиболее предпочтительным для начинающих предпринимателей является обращение за получением финансовых ресурсов в венчурные фонды и к бизнес ангелам. Венчурный капитал - это финансирование, которое инвестируется в стартапы и малые предприятия, которые обычно 
подвержены высокому риску, но также имеют потенциал для быстрого роста. Целью венчурных инвестиций является очень высокая прибыль для венчурной фирмы, обычно в форме приобретения всего стартапа или акций. Самое большое преимущество работы с фирмами венчурного капитала состоит в том, что, если стартап обанкротится, нет обязательств по возвращению инвестиций, потому что в отличие от займа, нет никаких обязательств по его возврату и инвестируются средства с осознанием высокого риска. Что еще более важно, инвесторы могут быть заинтересованы в том, как вы будете продвигать продукты и какие у вас планы по охвату клиентов [2]. Если продукт является инновационным и впервые апробируется на рынке, это может быть смело подчеркнуто в рекламной кампании для инвесторов. В зависимости от того, насколько хорошо будет представлено предложение и от восприятия инвестора, вполне вероятно, что предложение может быть отклонено или, инвестор попросить изменить некоторые детали. Каждый отказ - это возможность вернуться и проанализировать, где произошла ошибка, или найти более подходящего инвестора [2].

Венчурное финансирование, как и господдержка, осуществляется в несколько этапов:

- Генерация идей

- Запускать

- Нарастить

- Выход

Эman 1: Генерацчия идеи и представление бизнес-плана

Первым шагом в обращении к венчурному капиталу является представление бизнес-плана. План должен включать следующие пункты:

- Должно быть краткое резюме бизнес-предложения.

- Описание возможностей и рыночного потенциала и размера

- Обзор существующего и ожидаемого конкурентного сценария

- Подробные финансовые прогнозы

- Подробности управления компанией.

Венчурный капитал (далее - BK) проводит подробный анализ представленного плана, чтобы решить, принять проект или нет.
Эman 2: Вступительное собрание

После того как ВК проведет предварительное исследование и найдет проект в соответствии со своими предпочтениями, будет проведено индивидуальное совещание, на котором будет проведено подробное обсуждение проекта. После встречи ВК наконец решает, стоит ли продвигаться к стадии должной осмотрительности процесса.

Эman 3: Надлежащзая проверка

Этап комплексной проверки зависит от характера бизнес-предложения. Этот процесс включает в себя решение запросов, связанных с отзывами клиентов, оценками продуктов и бизнес-стратегий, собеседованиями с руководством и другими подобными обменами информацией в течение этого периода времени.

Этап 4: Сроки и финансирование

Если фаза должной осмотрительности является удовлетворительной, ВК предлагает список условий, который является необязательным документом, объясняющим основные положения и условия инвестиционного соглашения. Перечень условий, как правило, подлежит обсуждению и должен быть согласован всеми сторонами, после чего по завершении юридических документов и юридической экспертизы средства предоставляются [3]. После получения финансирования, реализации проекта и погашения всех долгов перед инвесторами предприятие остается под непосредственным управлением менеджера. Нужно отметить современные тенденции менеджмента и самого менеджера предприятия. Если раньше руководитель предприятия рассматривался как человек властный, влиятельный и нетерпящий ошибок, то сейчас руководителем приходится действовать более гибко, быть не «Боссом» и «Лидером». Наиболее полно охарактеризовал «Лидера» Джон Максвелл: - «Лидер - это тот, кто знает путь, идет своим путем и показывает путь».

Менеджмент в целом должен отличаться ориентированностью на непрерывное инновационное развитие, т.к. продукт или услуга, для реализации которого предприниматель обращался за финансированием, постепенно теряет свою актуальность, люди меняются - меняются вкусы и предпочтения. 
Поэтому необходимо постоянно развивать инновационную деятельность, разрабатывать и внедрять новые продукты и услуги. Инновационный менеджмент состоит из трех взаимосвязанных уровней, которые практически на всех предприятиях одинаковы:

1) предпринимательство (бизнес);

2) организационное управление;

3) практические действия.

Наличие первого уровня (предпринимательство) характерно для действующих предприятий, и заключается перестроение предприятия на инновационное развитие. Второй уровень организационное управление. Для действующих старых, действующих новых предприятий имеет то же значение, что и первый и заключается в создании на предприятии подразделений и отделов, занимающихся инновационным развитием деятельности предприятия. На данном уровне также осуществляется поиск соответствующих кадров и привлечение специалистов. Только созданному предприятию в этом плане сравнительно легче, так как перестроить небольшое производство не представляется слишком болезненным. Третий уровень характеризуется уже конкретными инновационными решениями и результатами. Бизнес сегодня значительно отличается от того, каким он был несколько десятилетий назад, что связано с трансформацией общества, его цифрового развития и, изменившиеся под весом данных факторов, предпринимательской культуры. Выстроить эффективный менеджмент сегодня и сложнее, и легче одновременно. Сложнее в том плане, что сегодня к работодателям предъявляются определенные требования со стороны надзорных органов по организацию рабочего процесса. Также на первый план выходит поиск и удержание на предприятии ценных сотрудников, у которых со временем появляется возможность диктовать свои условия руководству. Упрощено прежде всего за счет внедрения новых технологий и появление инновационных технологических решений.

\section{Библиографический список}

1. Финансирование малого бизнеса государством в 2019 году. [Электронный источник]. URL: https://vseproip.com/biznes-ip/maluy/finansirovanie-gosudarstvom.html.

2. Электронный ресурс. URL: https://www.educba.com/funding-requirements/.

3. Электронный ресурс. URL: https://www.edupristine.com/blog/venture-capital. 